\section{Science in Czechoslovakia}

SIR - It is no secret that the young, mainly democratic governments of central Europe have huge economic difficulties. The national economies change from central planning to a market economy slowly, and along untrodden paths. Capital is lacking, and unemployment rises, while people feel victimized and discontented. In such conditions, cuts are made in 'nonproductive' areas such as culture, education, science and research, and in health care.

The defeat of totalitarian regimes offers a great opportunity for redressing injustice but, when democracy is neither established nor generally accepted, it is also an opportunity for social climbers and their shrewd practices.

Economic transformation logically affects the position of science in society, the financial resources for research institutes and the standard of living of particular researchers. Today, science is a Cinderella, and there are even voices saying that scientists and researchers are unnecessary. This could become very dangerous and the solution is not clear.

The 'velvet revolution' in Czechoslovakia has not ended. If people band together, regardless of their political inclinations, they can exert enormous pressure on science-related issues, particularly with one or two well-timed anticommunist speeches and a seat or chair in some committee in a research institute, in the academy or at an influential ministry.

Grant committees are a good example. The idea of competition for financial support has been tested in the West. But the Czechoslovak Academy, for example, both offers and approves of grants - they are sometimes nicknamed "family favours".

To defend this scandalous practice, the academy's advocates say that pure science is hard to justify in a state with serious economic restraints. When the publications of the research institutes of the academy were assessed, those receiving grants often lagged behind those whose grant applications were rejected. No wonder then that the Ministry of Finance is cautious about its financial contribution to the academy.

The chaotic situation also makes possible the creation of new institutes, with new directors. If it is asserted that large research institutes are not productive, a statement that cannot easily be disproved, one institute can, with minimum effort, be reformed into several new ones, with more seats for directors and their deputies. 'Independent' international boards are then formed, from people chosen in advance.

Czechoslovakia needs the unbiased Czechoslovakia help of international scientific organization. Candidates for study trips outside the country are chosen by competition, and it is important that there should be an age limit, and that local institutions cannot influence the results. Otherwise, older scientists can easily win stipends, presenting themselves as victims of the former regime and neglecting to say that many of them had been party members and influential bosses. The personal economic benefits are obvious. Less obvious, though, are the benefits for their home institutes. Young researchers have also become aware of the new system. We are witnessing another wave of intellectual emigration from Czechoslovakia, this time for economic reasons. This is the sixth such wave in this century, and no country can survive repeated braindrains without serious damage.

What is even worse is inner emigration'. The economy is heading towards a market economy and free enterprise. International companies have quickly become established in Czechoslovakia and offer salaries to leading scientists up to ten times higher than those offered by the academy or research institutes. The maximum salary paid by the academy is about $£ 120$ a month.

It is hardly surprising that many scientists have discovered that they have a knack for enterpreneurship and start private businesses. The problem is that they often trade in the results of their ex-colleagues from research institutes. Legislation seems to be powerless or nonexistent.

To conclude, the standard of scientists in research institutes is being lowered and their average age is rising. There are some staff who had no relations with the previous regime, but many institutions still employ 'nomenclature' staff, who had accumulated a solid background under the communist regime. But not all scientists who enjoyed privileges under previous regimes were poor researchers. On the contrary, the privileges they earned through party membership (trips abroad, international congresses, material equipment, and so on) were effectively used by many of them.

It is to be hoped that the current problems of science in central Europe can be quickly remedied. Scientists need to avoid the mere imitation of Western scientific achievements and contribute to world science independently.

\section{Zdenko Vaněk}

Division of Microbial Physiology and Metabolites,

Czechoslovak Academy of Sciences, Institute of Microbiology,

14220 Praha 4 - Videňská 1083,

\section{Changing places}

SIR - In early April, I attended a conference ("Research horizons in life sciences) organized by COPUS (Committee On the Public Understanding of Science) to facilitate interaction between scientists and the media.

One theme seemed to recur, in various guises: the difficulty of reconciling the conflicting interests of the two factions. Journalists are primarly interested in 'news' and, almost by definition, this means rapidly changing events. In a scientific context, this implies something that happened or was discovered today, not yesterday or last week, in other words a 'breakthrough'.

A frequent complaint of scientists is that the bulk of research does not proceed in this fashion. The lay public has been conditioned, particularly by television, to believe that 'breakthroughs' are the everyday currency of science. This is the exception, rather than the rule. Research is, more commonly, an evolutionary process. Edison once pithily debunked a similar myth by saying that genius was " 1 per cent inspiration and 99 per cent perspiration".

A real problem of this kind of gradual development is that it is not readily newsworthy. Attemps to mould science to a news format reflect a lack of insight into scientific methods and the research process that can lead to distorted, inaccurate or sensationalist reporting of a scientist's work. Futhermore, by focusing solely on 'newsworthy' research, one is presented with a largely inaccurate image of science and scientists.

COPUS recognizes in its policy document that it must change scientists' perception of the need for a greater public understanding of science. A useful contribution to this end has been its media fellowship scheme in which academics are seconded to newspapers or television for several weeks to gain an awareness of how science is currently presented to the public.

Implicit in the media fellowship program is the premise that scientists should learn about journalism. As a scientist, I should like to suggest a reciprocal scheme whereby journalists are invited to spend, say, two weeks in a suitable scientific laboratory. More journalists might then appreciate not only how scientists think and interact but the nature of the research process. The presentation of the human face of scientists might help rid us of the tabloid 'boffin' tag. I venture that the 'diary' of such an exercise, far from being a dreary catalogue of routine, would be of general interest and, dare I say it, publishable. Jonathan Stamford

London Hospital Medical College,

Whitechapel, London E1 1BB, UK 